\title{
Total joint replacement improves pain, functional quality of life, and health utilities in patients with late-stage knee and hip osteoarthritis for up to 5 years
}

\author{
Audrey Neuprez, MD, MPH ${ }^{1,2}$ (D) Arnaud Henri Neuprez ${ }^{1} \cdot$ Jean-François Kaux, MD, PHD ${ }^{2} \cdot$ William Kurth, MD $^{3}$. \\ Christophe Daniel, $\mathrm{MD}^{3}$. Thierry Thirion, $\mathrm{MD}^{3}$. Jean-Pierre Huskin, $\mathrm{MD}^{3} \cdot$ Philippe Gillet, MD, $\mathrm{PHD}^{3}$. \\ Olivier Bruyère, $\mathrm{PHD}^{1}$. Jean-Yves Reginster, $\mathrm{MD}, \mathrm{PHD}^{1,4}$
}

Received: 12 August 2019 / Revised: 22 September 2019 / Accepted: 2 October 2019 / Published online: 13 November 2019

(C) International League of Associations for Rheumatology (ILAR) 2019

\begin{abstract}
Objectives To study and identify the determinants of the impact on pain, function, and quality of life of a prosthetic replacement surgery after 5 years of survival in patients with osteoarthritis (OA) of the lower limb.

Method In total, 626 osteoarthritic patients from a University Hospital, divided in 2 groups (according to surgical site), were prospectively followed for 5 years after hip $(n=346)$ or knee $(n=280)$ replacement. Validated specific Western Ontario and McMaster Universities Arthritis Index (WOMAC) and generic (SF-36 and EQ) instruments assessing quality of life were used prior to surgery and yearly, thereafter. We defined a good outcome as a clinically relevant improvement in WOMAC greater than or equal to the minimally important difference (MID). Regressions showed the relationships among preoperative, perioperative, and postoperative measures and the evolution of WOMAC scores after 5 years (percent change). We also examined any predictors of good outcomes.

Results The beneficial effect on quality of life observed during the first year after hip and knee arthroplasty (HA and KA) was maintained for up to 5 years. More than 3/4 of the patients in our study experienced a good outcome $(86.04 \%$ in HA group and $79.91 \%$ in KA group). Both the good outcome and the 5-year change in WOMAC are predicted by preoperative (i.e., radiological severity, comorbidities, disability, and level of education), perioperative (i.e., length of hospital stay and place of discharge), and postoperative (i.e., complications) variables in the two groups.

Conclusions Joint arthroplasty is a highly valuable therapeutic strategy for hip or knee OA patients who do not respond to pharmacological management. These results represent a step towards the collection of robust, scientifically sound data that will facilitate the completion of health economic analyses in the field of OA.
\end{abstract}

Audrey Neuprez, MD, MPH

audrey.neuprez@chuliege.be

1 Department of Public Health, Epidemiology and Health Economics, WHO Collaborating Center for Public Health Aspects of Musculo-Skeletal Health and Aging, University of Liège, Liège, Belgium

2 Rehabilitation and Sports Traumatology Department, University Hospital of Liège, Liège, Belgium

3 Orthopedic Surgery Department, University Hospital of Liège, Liège, Belgium

4 Chair for Biomarkers of Chronic Diseases, Biochemistry Department, College of Science, King Saud University, Riyadh, Saudi Arabia 


\section{Key Points:}

- This study reports the long term outcomes of hip and knee replacement surgery in late-stage OA.

- We identified pre-, per-, and post-operative determinants which contribute to a greater improvement in pain and function, hence increasing patients' satisfaction.

- These results could contribute to select an OA population which has a high probability to get an optimal benefit from total joint replacement.

Keywords Arthroplasty $\cdot$ Hip $\cdot$ Knee $\cdot$ Osteoarthritis $\cdot$ Quality of life

\section{Introduction}

Osteoarthritis (OA) affects 240 million people globally, approximately $10 \%$ of men and $18 \%$ of women, especially elderly patients. OA is the third most common diagnosis made by general practitioners in older patients $[1,2]$. Due to an aging society and obesity, the prevalence rates of knee (KOA) and hip (HOA) OA are continuously rising. OA of the lower limb represents an important clinical, social, ethical, and economic burden from a societal perspective [3]. Different therapeutic options have been proposed by scientific societies [4-6]. Surgical management, including joint replacement, is recommended for patients who do not appropriately respond to pharmacological management or those who have late-stage OA. In most developed countries, the number of hip or knee arthroplasties (HA and KA) has increased substantially over the past few years, along with increased costs [7]. The outcomes of surgical management are generally recognized as very satisfactory, with an increase in the life span. In addition, $\mathrm{HA}$ is a safe and reliable procedure for the treatment of endstage arthritis in the young with good to excellent mid-term results [8]. However, arthroplasty can result in adverse health consequences; the most problematic is revision surgery [9]. Therefore, it is important to carefully evaluate the patient's benefits of these surgical interventions. In a previous study, we demonstrated fast (from 3 months), substantial, and shortterm benefits of $\mathrm{HA}$ and KA on parameters reflecting quality of life and health utility [10]. We have continued a 5-year follow-up of this large number of OA patients, from both genders, who underwent joint replacement of the knee or hip. The objective of the present study was to determine whether the benefits observed during the first year were maintained or improved over time and to clarify their determinants. Our purpose was not to compare HA and KA.

\section{Materials and methods}

After prior approval from the Institutional Review Board (IRB), 845 consecutive patients hospitalized at the University Hospital of Liege in Belgium were considered eligible for the study. The sample size was evaluated based on previous publications looking at similar parameters. The patients, aged 18 years older, presented with end-stage HOA or KOA (diagnosis based on the clinical and radiographic criteria of the American College of Rheumatology and established in case of inappropriate response to pharmacological management, according to scientific guidelines [4-6]) needed joint replacement. A total of 626 subjects fulfilled the inclusion criteria and received the first questionnaire. They were divided in 2 groups (according to surgical site) and were monitored over time from the day before surgery to 5 years after surgery. The full details of the methodology for recruitment and follow-up were previously described [10, 11]. During the 5-year follow-up, the evaluation of postoperative outcomes continued through mail on a yearly basis.

The data collected referred to and related to patient's characteristics, comorbidities, radiological severity, quality of life, and the clinical impacts of OA. We recorded age, gender, body mass index (BMI), duration of knee or hip complaints, and previous traumatic or surgical history of the lower limbs (information was also obtained by consulting the medical files).

The Functional Comorbidity Index (FCI) was used to record comorbidities throughout the 5 years. This specific, validated instrument was developed to assess the status of patients undergoing joint replacement. The score ranges from 0 to 18 , depending on the presence of 18 diagnoses associated with declining function [12]. X-rays of the target joint were scored according to the Kellgren-Lawrence (KL) grading system [13].

The occurrence of complications was registered and monitored during the 5-year follow-up. These were structured and clustered into 3 categories: early postoperative complications (within 30 days of surgery), 1-year postoperative complications, and late-onset complications (up to 5 years).

We chose generic instruments for the assessment of quality of life ((36-item short-form health survey (SF-36)) and utility (EuroQol (EQ) health-related quality of life instrument). The Western Ontario and Mac Master Universities Arthritis Questionnaire (WOMAC) was selected as a specific OA instrument. The WOMAC covered 3 specific fields: pain, stiffness, and physical function [14]. Lower values reflect a better health status (scores range between 0 and 96). The SF-36 is a popular tool for assessing health-related quality of life (HRQOL) in many physical health conditions [15]. The 8 individual subscales are divided across the physical domains 
of physical function (PF), role physical (RP), bodily pain (BP), and global health (GH) and the psychological domains of vitality (V), social function (SF), role emotional (RE), and mental health $(\mathrm{MH})$. Higher scores represent better health (scores range from 0 to 100). The EQ measures utility in 2 ways: a health state classification (in five domains: 5D) ranging from 0 to 1 , in which 1 represents full health and 0 is death), and an evaluation using a visual analog scale (VAS; ranging from 0 to 100 according to the same logic) [16].

We determined the percentage variation in the total WOMAC score after 5 years. The concept of a "good outcome", which is established if the enhancement in total WOMAC is greater than or equal to the minimally important difference (MID), makes it possible to see if the WOMAC improvement is clinically relevant. MID represents one-half of the SD of the difference between the pre-surgery summary score and the 5-year post-surgery summary score. MID allows us to interpret the clinical significance of the mean differences or to determine the proportion of patients who experience clinically important changes [17].

\section{Statistical analysis}

We recorded basic demographic variables including age, gender, study level, income level, BMI, FCI, KL grade, and surgical or traumatic history. We examined intraoperative variables including the type of prosthesis, type of fixation, type of weight-bearing surfaces, and postoperative variables including hospital length of stay (LOS), location of discharge (discharged to home or to another facility), and complications. After the verification of data normality and homogeneity, we processed nonparametric statistical analysis. Continuous variables are expressed as the means with standard deviations (SDs) for the visual relevance. The proportions that met our criteria for a good outcome were calculated with $95 \%$ confidence intervals (95\% CIs) for hip and knee replacement recipients separately. The comparisons between baseline measures (EQ and WOMAC) and follow-up measures (1 year to 5 years) were conducted using Wilcoxon signed-rank tests (2 samples). Second, data from the 1-year follow-up and the 2to 5-year follow-up were compared using Friedman's analysis of variance and the Wilcoxon signed-rank test. Univariate and multivariable regression analyses were performed to determine whether preoperative patient's characteristics, intraoperative, or postoperative variables influenced our main outcome at 5 years (variation in the total WOMAC score). A significance level of 0.25 was used to include variables in the regression model before a backward selection procedure. Then, we performed secondary analyses seeking associations between these factors and good outcome using binary logistic backward regression modeling. Finally, as previously performed, we explored the profile of patients with long-term complications using the same statistical strategy [10]. The odds ratios
(ORs) associated with each of the identified predictors were determined using logit regression. The data were analyzed using Statistica version 13, on a Windows platform. The level of statistical significance was set at $p<0.05$, except for the Wilcoxon signed-rank tests. For those, we adjusted the statistical significance level based on the number of time point comparisons (Bonferroni correction: $p<0.05 / 4=0.0125$ and $p<0.05 / 5=0.01)$.

\section{Results}

\section{Population characteristics}

Of 845 individuals with lower limb OA who were invited to participate, 219 were not included due to language problems or insufficient literacy $(n=26 ; 3.08 \%)$, lack of consent ( $n=$ $161 ; 19.05 \%$ ), or reduced preoperative cognitive, sensory, or physical capacity ( $n=32 ; 3.79 \%)$. Of the remaining 626 individuals, 280 received KA (44.73\%) and 346 underwent HA (55.27\%). The participants' median (P25-P75) age was 66 (59-73) years; $56.8 \%$ of the patients were female. Table 1 shows the characteristics of the study population at baseline and the specified intraoperative and postoperative parameters, which are already largely detailed in the two previous publications on this patient cohort.

$H A$, hip arthroplasty; $K A$, knee arthroplasty; $B M I$, body mass index; $K L$, Kellgren-Lawrence; $C P R S$, complex regional pain syndrome

\section{Persistence}

We are able to follow $76 \%$ of our population to the end of 5 years (Fig. 1). The reasons for the lack of participation are related to willingness, time consumption, or personal problems. Only 15 patients in the KA group (5\%) and 5 patients in the HA group (1\%) decided to discontinue the study due to problems directly related to the surgical procedure. The 147 patients who prematurely discontinued the study were older (68.02 vs 64.84 years, $p<0.05$ ), had more comorbidities ( 2.79 vs $2.42, p<0.05$ ), and had a lower quality of life (regarding the EQ instrument: 60.92 vs 64.46 for EQ-VAS and 0.38 vs 0.46 for EQ-5D). However, we did not observe any difference in radiological severity $(\mathrm{KL}, p=0.33$ ) or in pain, function, or stiffness (WOMAC, $p=0.12$ ).

\section{EQ evolution}

The EQ-5D/VAS health utility scores were significantly improved at the $12^{\text {th }}$ postoperative month in both groups $(p<$ $0.01)$. The values remained stable for up to 5 years in the KA group ( $p=0.11$ for EQ-VAS and $p=0.28$ for EQ-5D). In the HA group, the improvement was actually maximal at the 1- 
Table 1 Characteristics of the study population at baseline and specified intraoperative and postoperative parameters

Va

\begin{tabular}{|c|c|}
\hline $\mathrm{KA}(n=280,44.73 \%)$ & HA $(n=346,55.27 \%)$ \\
\hline$\%$ & $\%$ \\
\hline or Mean $\pm \mathrm{SD}$ & or Mean \pm SD \\
\hline
\end{tabular}

Patient's characteristics

\begin{tabular}{|c|c|c|c|c|}
\hline \multirow{2}{*}{$\begin{array}{l}\text { Age at the time of operation (years) } \\
\text { Gender: female }\end{array}$} & \multicolumn{2}{|c|}{$66.74 \pm 8.95$} & \multicolumn{2}{|c|}{$64.64 \pm 10.85$} \\
\hline & 152 & 54.29 & 204 & 58.96 \\
\hline \multicolumn{5}{|l|}{ Educational level } \\
\hline No education & 3 & 1.07 & 0 & 0 \\
\hline Primary school & 44 & 15.71 & 34 & 9.83 \\
\hline Lower secondary school & 68 & 24.29 & 76 & 21.97 \\
\hline Upper secondary school & 85 & 30.36 & 118 & 34.10 \\
\hline Higher education & 80 & 28.57 & 118 & 34.10 \\
\hline BMI & \multicolumn{2}{|c|}{$29.31 \pm 4.71$} & \multicolumn{2}{|c|}{$27.42 \pm 4.79$} \\
\hline Surgical/traumatic background & 97 & 36.64 & 22 & 6.36 \\
\hline FCI & \multicolumn{2}{|c|}{$2.41 \pm 1.25$} & \multicolumn{2}{|c|}{$2.63 \pm 1.25$} \\
\hline KL score (distribution) & \multicolumn{2}{|c|}{$n=273$} & \multicolumn{2}{|c|}{$n=339$} \\
\hline 1 & 12 & 4.4 & 23 & 6.78 \\
\hline 2 & 43 & 15.75 & 83 & 24.48 \\
\hline 3 & 188 & 68.86 & 123 & 36.28 \\
\hline 4 & 30 & 10.99 & 110 & 32.45 \\
\hline \multicolumn{5}{|l|}{ Procedure characteristics } \\
\hline \multicolumn{5}{|l|}{ Type of prosthesis } \\
\hline Unicompartimental (KA group) or Resurfacing (HA group) & 14 & 5 & 9 & 2.60 \\
\hline Cemented fixation & 195 & 69.64 & 60 & 17.34 \\
\hline \multicolumn{5}{|l|}{ Weight-bearing surfaces } \\
\hline Ceramic/ceramic & & & 200 & 57.97 \\
\hline Metal/metal & & & 66 & 19.13 \\
\hline Metal/polyethylene & & & 27 & 7.83 \\
\hline Polyethylene/ceramic & & & 52 & 15.07 \\
\hline \multicolumn{5}{|l|}{ Postoperative characteristics } \\
\hline Length of hospital stay (days) & \multicolumn{2}{|c|}{$8.62 \pm 3.03$} & \multicolumn{2}{|c|}{$7.51 \pm 7.02$} \\
\hline Discharge status: nursing home or rehabilitation facility & 93 & 33.45 & 80 & 23.12 \\
\hline Early postoperative complication & 38 & 13.57 & 38 & 10.98 \\
\hline 1st year postoperative complication & 61 & 21.79 & 25 & 7.23 \\
\hline Late-onset complication & 23 & 8.21 & 37 & 10.72 \\
\hline Aseptic loosening & 3 & 1.07 & & \\
\hline CRPS & 1 & 0.36 & & \\
\hline Periprosthetic fracture & 1 & 0.36 & 2 & 0.58 \\
\hline Infection & 2 & 0.71 & & \\
\hline Patellar complaint or knee resurfacing & 9 & 3.21 & & \\
\hline Muscle or ligament problem & 6 & 2.14 & 30 & 8.69 \\
\hline Dislocation & & & 3 & 0.87 \\
\hline Heterotopic ossification & 1 & 0.36 & 1 & 0.29 \\
\hline Death & & & 1 & 0.29 \\
\hline Major complication & 28 & 8.12 & 30 & 10.71 \\
\hline
\end{tabular}

$H A$, hip arthroplasty; $K A$, knee arthroplasty; $B M I$, body mass index; $K L$, Kellgren-Lawrence; $C P R S$, complex regional pain syndrome. Number of patients for whom preoperative radiography was available set in italic year postsurgical follow-up. After that, the EQ-5D and VAS scores decreased slightly and were significantly better compared with that in the 1-year follow-up ( $p=0.04$ for EQ-5D and $<0.05$ for EQ-VAS). The beneficial effect 


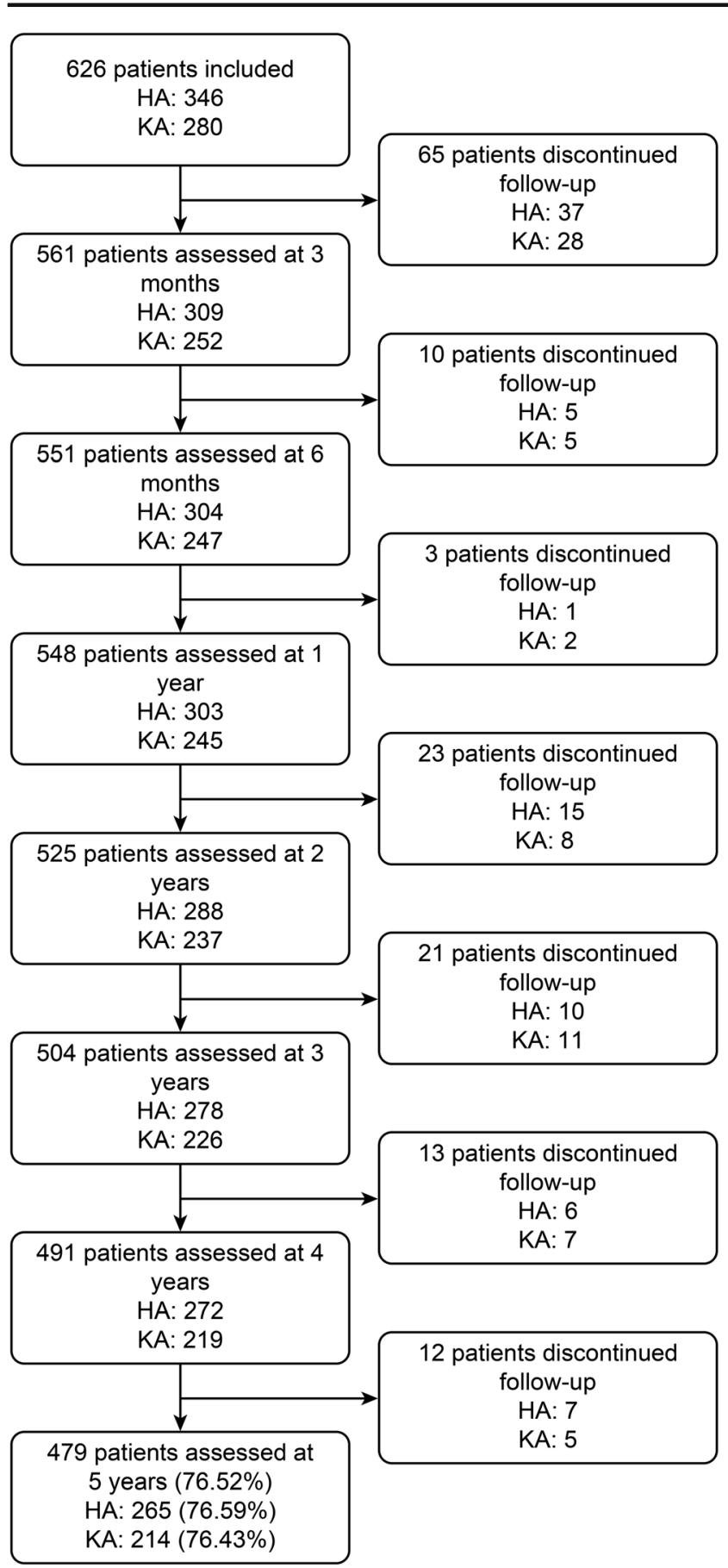

Fig. 1 Flowchart representing follow-up of patients

observed after 1 year in terms of quality of life were maintained for up to 5 years of follow-up and was still significantly higher than the clinical preoperative status in the two groups $(p<0.01)$. At this time point, utility (EQ-5D) was improved to $48 \%$ (HA) and $39 \%$ (KA) compared with what was recorded at baseline (Fig. 2).

\section{WOMAC evolution}

Compared with the baseline scores, the total WOMAC score and all of the subscale scores were significantly improved 12 months after surgery $(p<0.01)$ and further improved over time $(p<0.01)$ compared with the baseline scores. After 3 years (KA) and 5 years (HA), some parameters were slightly better than the improvement recorded after 1 year $(p<0.01)$ (Fig. 3).

\section{SF-36 evolution}

Regarding the SF-36, in the HA group, maximal improvements were observed 1 year after surgery in 3 physical domains $(\mathrm{PF} / \mathrm{BP} / \mathrm{GH})$, in the mental domain $(\mathrm{MH})$ and in the overall health change. This period of maximal improvement was followed by a gradual diminution with better data at 5 years than at the preoperative level. The maximum values in the last physical domain (RP) and 2 other mental domains (SF/ $\mathrm{RE})$ were achieved at 3 years. In the KA group, the peak values were observed later (1 year for MH and VT; 3 years for BP; and 4 years for PF, RP, SF, and, RE). In the two study groups, the general health perceptions were maximal at 1 year and returned to the preoperative levels at 5 years.

\section{WOMAC determinants}

In the final multivariate linear regression (Table 2), severe radiological OA at baseline and the absence of late postoperative complications were positive predictive factors of a beneficial outcome after 60 months in patients with HA.

WOMAC, Western Ontario and McMaster Universities Osteoarthritis Index; $H A$, hip arthroplasty; $K A$, knee arthroplasty; $F C I$, functional comorbidity index; 1-y, 1-year

In patients with $\mathrm{KA}$, a low number of comorbidities, an early discharge from the hospital, a discharge to home, and the absence of complications (1-year and late) were identified as positive predictive factors. Patients with a greater preoperative stiffness on WOMAC were more likely to experience greater improvement. The level of education favorably influences the evolution of outcome scores.

These parameters explain the $17 \%$ and $24 \%$ of the variance of the WOMAC total score in the HA group and KA group, respectively.

\section{Good outcome determinants}

The mean improvements in hip/knee WOMAC summary scores were $37.68 \pm 22.75$ and $25.78 \pm 21.84$, respectively. The calculated MID for WOMAC summary scores is an 11point improvement for the hip and a 10-point improvement for the knee. More than 3/4 of patients meet the MID criterion for good outcome $(86.04 \%$, 95\% CI: $81.86-90.21$ in the HA group; and $79.91 \%$, 95\% CI: 74.54-85.28 in the KA group).

The determinants of "good outcome" in the HA group were a higher preoperative disability score (OR 1.04, 95\% CI 1$1.07, p=0.03$ ), lack of comorbidities (OR $0.71,95 \%$ CI $0.51-$ 

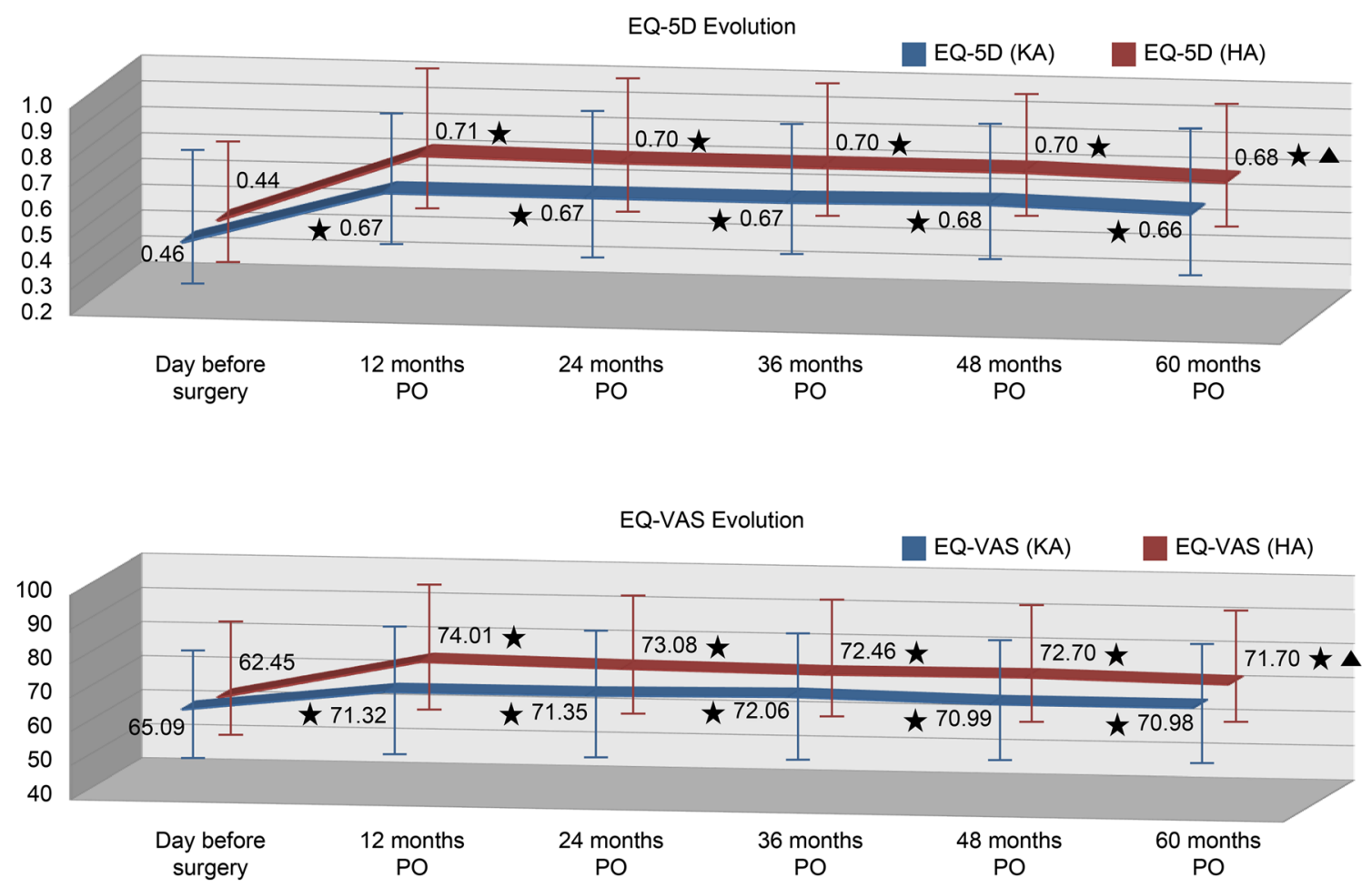

Fig. 2 EQ-5D and EQ-VAS evolution over time (mean and SD). EQVAS EuroQol visual analog scale; scored from 0 to 100 , EQ-5D EuroQol 5 dimensions of health; scored from 0 to $1, \mathrm{PO}$ postoperative. *Significant

difference $(p<0.01)$ compared with baseline (Wilcoxon test). $\Delta$ Significant difference $(p<0.01)$ compared with the 1 -year follow-up (Wilcoxon test)

$0.97, p=0.03)$, and the absence of postoperative complications (OR 0.17, 95\% CI 0.07-0.41, $p<0.001$ ).

In patients with $\mathrm{KA}$, the degree of preoperative stiffness (OR 1.42, 95\% CI 1.13-1.77, $p=0.002$ ), level of education, degree of radiological severity (OR $2.4395 \%$ CI $1.34-4.38, p$ $=0.003$ ), lack of comorbidities (OR 0.67, 95\% CI 0.51-0.87, $p=0.003$ ), place of discharge (OR 3.89, 95\% CI 1.70-8.92, $p$ $=0.001$ ), and length of hospital stay (OR $0.88,95 \%$ CI $0.77-$ $0.99, p=0.046)$ were identified as predictors for good outcome.

\section{Late-onset complications}

We previously published the rate of early complications in both procedures [10]. At the 5-year postsurgical follow-up (Table 1), the complication rate was $10.72 \%$ for patients who experienced HA and $8.21 \%$ for those who underwent KA. In the HA group, the most frequent complication was dislocation $(1.16 \%)$. A total of $8.99 \%$ of patients in the HA group had persistent pain due to muscle/ligament disorder. The most frequent complication in the KA group was patellar pain $(3.23 \%)$. Muscle/ligament disorder was present in $2.15 \%$ of the patients. Throughout the study, 6 patients were affected by infectious complications: 4 during the 1 st year and 2 during the long-term follow-up ( 2 in the HA group and 4 in the KA group), i.e., less than $1 \%$ of our cohort.

\section{Discussion}

In our large study, we noted that the positive impact of HA and KA on HRQOL observed after 3 months continues and remains statistically significant over time (up to 5 years) compared with the clinical condition before surgery [10]. In particular, quality of life and specific OA symptoms (pain, stiffness, and function) were better than they were before arthroplasty. Earlier analyses were not performed given that no substantially different outcomes between the 12- and 48month follow-up were observed. These findings are entirely consistent with a recent review [18].

Most studies published in recent years have established a positive impact of HA and KA on HRQOL [19, 20]. Diseasespecific measures are more accurate for assessing immediate effects, whereas generic measures reveal the long-term effects of an intervention in overall function. All health domains on the SF-36 were superior or similar to those at baseline over a follow-up of 5 years. As one might expect, the physical domains (PF, RP, BP, and GH) reveal the largest benefits. In addition, benefit has also been observed in the psychosocial domains (VT, RE, MH, and SF) after HA and KA, even though this may not be the primary goal of surgery. The stabilization phase observed from 12 months to 5 years after surgery can be attributed to aging (e.g., an increasing number of comorbidities and multiple sites of OA). However, HRQOL remains above the preoperative level. Logically, 

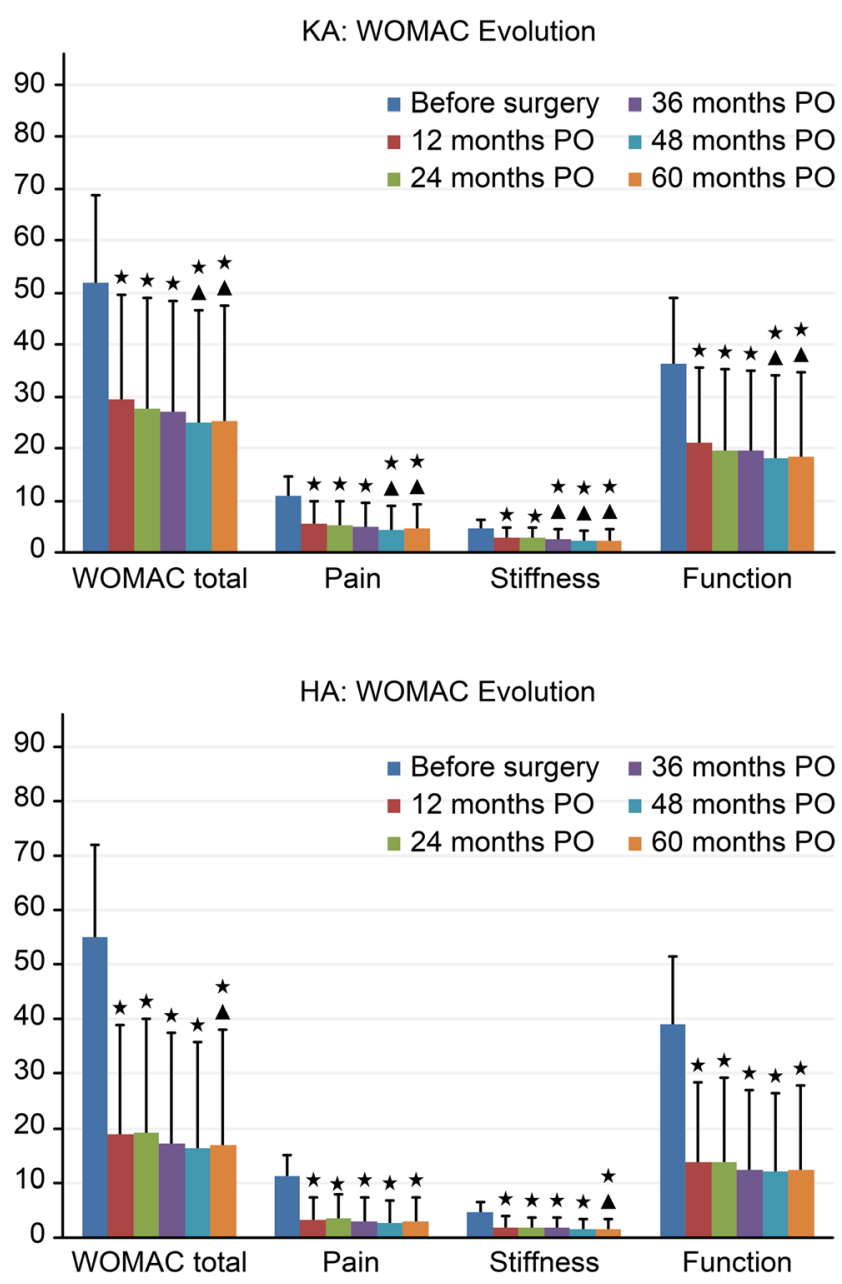

Fig. 3 WOMAC and component evolution over time (mean and standard deviation). WOMAC Western Ontario and McMaster Universities Osteoarthritis Index; scored from 0 to 96 . * Significant difference $(p<$ $0.01)$ compared with baseline (Wilcoxon test). $\Delta$ Significant difference $(p<0.01)$ compared with the 1-year follow-up (Wilcoxon test) physical components experience the greatest improvements, which is consistent with previous studies [19, 20].

The improvement also applies to EQ and goes in the same direction. These data may contribute to the conduct of health economics studies with the objective of evaluating whether arthroplasty of the lower limb in patients with OA can be considered a cost-effective procedure with a quality-adjusted life-year (QALY) gain [21]. This surgery could then be compared to other surgical procedures that are frequently conducted in a population of the same age with the objective to better allocate health resources. Similar analyses were conducted in the musculoskeletal field, as was the case for lumbar surgery in patients presenting with spinal stenosis [22].

Regarding WOMAC and its subscales, we observed a shortterm benefit that even improved until 60 months of follow-up. Most studies also described improvements in WOMAC after HA for 12 to 18 months postoperation with a subsequent plateau effect [19]. Regarding KA, the majority of benefits were demonstrated within 1 year of surgery. Following this, HRQOL was reported to slightly improve, to be maintained, or to decline but remains superior to preoperative levels [20].

Interpreting HRQOL scores is a challenging task. Multiple definitions have been proposed to evaluate lower limb arthroplasty benefits, including improvements in symptoms, quality of life, and patient satisfaction [17, 23]. Because joint pain is the most common reason people seek arthroplasty, it seems reasonable that evaluation of the surgical benefits incorporates improvement in pain [24]. The MID, defined in 2005 from the MCID, facilitated understanding of the importance of intervention effects, particularly patient-reported outcomes scores such as WOMAC scores[17]. In our study, we sought to determine the principal drivers of long-term outcomes,
Table 2 Prediction of a higher variation in WOMAC total score 5 years after $\mathrm{HA}$ and $\mathrm{KA}$ in the multivariate analysis (final model).

\begin{tabular}{|c|c|c|}
\hline \multirow[t]{2}{*}{ Predictors } & \multicolumn{2}{|c|}{ Postoperative WOMAC total score } \\
\hline & B $(95 \%$ confidence interval) & $p$ value \\
\hline \multicolumn{3}{|l|}{ KA model $\left(\mathrm{R}^{2}=0.24\right)$} \\
\hline Level of education & 7.33 (1.99 to 12.38$)$ & $<0.01$ \\
\hline FCI & $-6.01(-9.66$ to -2.37$)$ & $<0.01$ \\
\hline Length of stay & $-2.18(-4.21$ to -0.15$)$ & 0.04 \\
\hline Place of discharge following hospital stay & $-20.31(-32.02$ to -8.60$)$ & $<0.001$ \\
\hline 1-y postoperative complications & $-18.92(-31.70$ to -6.14$)$ & $<0.01$ \\
\hline Late postoperative complications & $-27.43(-46.44$ to -8.42$)$ & $<0.01$ \\
\hline Preoperative stiffness & $4.13(1.11$ to 6.98$)$ & $<0.01$ \\
\hline Constant & $60.74(33.11$ to 88.36$)$ & $<0.001$ \\
\hline \multicolumn{3}{|l|}{ HA model $\left(\mathrm{R}^{2}=0.17\right)$} \\
\hline Radiological severity & $5.11(0.60$ to 9.62$)$ & 0.03 \\
\hline Late postoperative complications & $-42.01(-54.37$ to -29.65$)$ & $<0.001$ \\
\hline Constant & $59.73(45.81$ to 73.64$)$ & $<0.001$ \\
\hline
\end{tabular}

WOMAC, Western Ontario and McMaster Universities Osteoarthritis Index; HA, hip arthroplasty; KA, knee arthroplasty; FCI, functional comorbidity index; 1-y, 1-year 
particularly the 5-year WOMAC score and the achievement of a "good" outcome, which is defined as a clinically important improvement in WOMAC. More than 3/4 of the patients in our study met the MID criterion for a good outcome. This rate is consistent with that of the previously published patientreported outcomes after lower limb arthroplasty [25].

Various preoperative, intraoperative, and postoperative variables can predict patients who experience good 5year outcomes. Regarding the predictors for 5-year outcomes, we found common parameters in HA and KA patients, such as radiological severity, postoperative complications, preoperative clinical parameters, and comorbidities.

Among the preoperative parameters, worse preoperative function and radiological severity of OA were associated with larger postoperative improvement in the HA group. This finding is consistent with what has been published in a recent review [26], although some authors do not agree with this analysis [27]. Postoperative complications also impacted the outcome at 5 years.

Regarding intraoperative and postoperative variables in the KA group, a long hospital stay, a high preoperative stiffness, and a discharge to another facility other than home and the first-year complications are significant predictors of a poor outcome after 5 years. We observed that the radiological severity of KOA is a positive predictor for "good outcome". Previously, preoperative arthritis severity was observed as a predictor of KA satisfaction [28]. The study level also affected outcome evolution in the KA group.

The number of comorbidities appears to have a long-term effect on patient outcome after arthroplasty. This result is consistent with another study, showing that comorbidities were one of the predictors that are significantly associated with smaller QALY gains after KA [29]. The association between a higher number of comorbidities and worse outcomes seems to be stronger in HA than in KA [30]. Presurgical comorbidities must not be an overall hindrance to arthroplasty because the mortality rates have decreased substantially over the past two decades [31]. Nonetheless, it should not be forgotten that patients with quite a few comorbidities reported more complications [32], which is also the case in our study. The type of prosthesis did not influence the outcome.

We did not demonstrate any influence of age, gender, or BMI on the postoperative outcome, as other studies have [26]. Obesity is associated with an increased risk of late-life mobility limitation after arthroplasty [33]. We did not find any impact of it in our study.

Dowsey elegantly addressed a similar issue from an alternative perspective in 2016 [34]. He developed and validated a prognostic tool to predict a nonresponse, 1 year after knee surgery. This approach could be considered in our population to identify the determinants of a bad result (opposite to the "good result"). In the future, this strategy could be applied to both hip and knee arthroplasties in a long-term perspective to identify modifiable risk factors predicting a poor outcome. This may subsequently impact on clinical practice. The goal would be to define threshold values, for some amendable variables, above or below which a greater probability of a lesser response to surgery occurs, hence allowing to correct these parameters before joint replacement.

The main strength of our research is the population profile. This study population is homogenous, and the surgical procedures were performed in the same surgical center, applying a standardized surgical and rehabilitation protocol. The prospective longitudinal design ( 5 years) with preoperative data, follow-up time points that were pre-determined at baseline (with repeated attempts at contact to minimize loss to follow-up), and the large sample size are also major assets. This large cohort allows comparisons with other studies, most of which include fewer patients. The preliminary results are encouraging. Another major strength is the rate of retention that was achieved. We were able to retain a large subset of our population ( $76 \%$ ) until the end of the follow-up ( 5 years). This retention compares favorably with that observed in other studies $[19,20,26]$. We use previously validated HRQOL instruments, including a generic instrument (SF-36), to facilitate the holistic assessment of the health dimensions according to the WHO's HRQOL definition [35].

In contrast, strengths can be turned into weaknesses. A bias may result from a single center study [36]. Regarding the sample size, a number of patients less than 500 are a potential source of bias in hip replacement studies and likewise for a number less than 270 in knee replacement studies. We did not achieve this number in the HA group, but it remains above the number of patients in the majority of previously published quality studies $[19,20]$. In the same vein, a loss of $<15 \%$ of patients to follow-up is considered ideal for treatment analyses according to guidelines [37]. However, this theoretical threshold ignores the length of follow-up. Accordingly, losing less than $20 \%$ of patients to follow-up at 1 year is considered to represent a low risk of bias. For a longer follow-up, an additional $10 \%$ loss to follow-up for each additional year is tolerated [26]. We are largely below this threshold for our 5-year study: $24 \%$ of KA patients and $23 \%$ of HA patients were lost to follow-up, and $5 \%$ and $1 \%$, respectively, had arthroplasty complications. The patients who discontinued the study were an average older, had more comorbidities, and had a reduced quality of life. However, their radiological and clinical (pain, stiffness, and function) profiles were similar to those who continued the study. Of course, we agree that patients who are lost to follow-up are more likely to be ill, less satisfied, or have poor outcomes. Inevitably, this can result in the discreet selection bias common to prospective cohort studies. Therefore, satisfied patients with good outcomes may be over-represented [38]. Perhaps, it would have been better to opt for telephone interviews to minimize the loss to follow-up. 
However, the mailed questionnaire reduced the recruitment effort compared with the telephone interview [39]. Additionally, this study does not include a control group. It would be interesting to compare the evolution of quality of life on a reference population. In this specific case, a control population seems a priori impossible for a variety of reasons. Sham operations are unthinkable for ethical reasons. On the other hand, surgery is proposed when patients are not responding to medications. It is inconceivable to leave patients at an advanced stage of disease and not to intervene. Last but not the least, the population of inoperable patients with end-stage OA would be significantly different. The comparisons can be quite hazardous given the differences in comorbidities and potential contraindications. Finally, assessing outcomes through self-reported questionnaires may bias the results due to response shift [40].

\section{Conclusions}

In our large prospective population cohort that received hip or knee replacement, $75 \%$ of the patients experienced a good outcome 5 years after surgery. Thus, lower limb replacement surgery benefits a large part of the community and is a therapeutic alternative not to be neglected in the management of OA. This procedure may be recommended for patients who do not respond to pharmacological treatment and for those who have a late-stage OA or contraindications to medications. These results provide information that can help determine the optimal timing of surgery through the preoperative patient status.

The findings represent a step towards the collection of robust, scientifically sound data that will pave the way for the completion of health economic analyses in the field of OA. In a cost-conscious approach, health-care resources must be more substantial and better targeted to allow health interventions to return the maximum benefit. In this context, the need to identify patients with a high propensity to be good responders makes sense from an economic perspective. Thus, this study offers a wide range of future perspectives.

Additionally, pharmacoeconomic modulation requires robust data to determine the effect on quality of life. The data generated during 5 years of follow-up appeared to provide such material. This study demonstrates the efficiency of replacement surgery compared with alternative strategies (musculoskeletal area or many other areas of medicine).

Author contributions AN participated in the design of the study, analysis and interpretation of the data, and manuscript preparation.

AHN participated in the analysis of the data and revising of the manuscript.

WK, CD, TT, JPH, JFK, and PG participated in the design of the study and revising of the manuscript.
OB and JYR participated in the design of the study, interpretation of the data, and manuscript preparation.

All authors read and approved the final manuscript.

\section{Compliance with ethical standards}

\section{Disclosures None}

Ethical approval The study was approved by the University Hospital of Liege Ethics Committee (approval number B70720084766).

Informed consent Written informed consent was obtained from all participants.

\section{References}

1. Nelson AE (2018) Osteoarthritis year in review 2017: clinical. Osteoarthr Cartil 26:319-325. https://doi.org/10.1016/j.joca.2017. 11.014

2. Liu CY, Li CD, Wang L, Ren S, Yu FB, Li JG, Ma JX, Ma XL (2018) Function scores of different surgeries in the treatment of knee osteoarthritis: a PRISMA-compliant systematic review and network-meta analysis. Medicine (Baltimore) 97:e10828. https:// doi.org/10.1097/MD.0000000000010828

3. Cross M, Smith E, Hoy D, Nolte S, Ackerman I, Fransen M, Bridgett L, Williams S, Guillemin F, Hill CL, Laslett LL, Jones G, Cicuttini F, Osborne R, Vos T, Buchbinder R, Woolf A, March L (2014) The global burden of hip and knee osteoarthritis: estimates from the global burden of disease 2010 study. Ann Rheum Dis 73: 1323-1330. https://doi.org/10.1136/annrheumdis-2013-204763

4. Bruyere O, Honvo G, Veronese N et al (2019) An updated algorithm recommendation for the management of knee osteoarthritis from the European Society for Clinical and Economic Aspects of Osteoporosis, Osteoarthritis and Musculoskeletal Diseases (ESCEO). Semin Arthritis Rheum. https://doi.org/10.1016/j. semarthrit.2019.04.008

5. Zhang W, Doherty M, Arden N, Bannwarth B, Bijlsma J, Gunther KP, Hauselmann HJ, Herrero-Beaumont G, Jordan K, Kaklamanis P, Leeb B, Lequesne M, Lohmander S, Mazieres B, Martin-Mola E, Pavelka K, Pendleton A, Punzi L, Swoboda B, Varatojo R, Verbruggen G, Zimmermann-Gorska I, Dougados M, EULAR Standing Committee for International Clinical Studies Including Therapeutics (ESCISIT) (2005) EULAR evidence based recommendations for the management of hip osteoarthritis: report of a task force of the EULAR Standing Committee for International Clinical Studies Including Therapeutics (ESCISIT). Ann Rheum Dis 64:669-681. https://doi.org/10.1136/ard.2004.028886

6. Jordan KM, Arden NK, Doherty M, Bannwarth B, Bijlsma JW, Dieppe P, Gunther K, Hauselmann H, Herrero-Beaumont G, Kaklamanis P, Lohmander S, Leeb B, Lequesne M, Mazieres B, Martin-Mola E, Pavelka K, Pendleton A, Punzi L, Serni U, Swoboda B, Verbruggen G, Zimmerman-Gorska I, Dougados M, Standing Committee for International Clinical Studies Including Therapeutic Trials ESCISIT (2003) EULAR Recommendations 2003: an evidence based approach to the management of knee osteoarthritis: report of a Task Force of the Standing Committee for International Clinical Studies Including Therapeutic Trials (ESCISIT). Ann Rheum Dis 62:1145-1155

7. Hiligsmann M, Cooper C, Arden N, Boers M, Branco JC, Luisa Brandi $\mathrm{M}$, Bruyère $\mathrm{O}$, Guillemin $\mathrm{F}$, Hochberg MC, Hunter DJ, Kanis JA, Kvien TK, Laslop A, Pelletier JP, Pinto D, ReiterNiesert S, Rizzoli R, Rovati LC, Severens JL, Silverman S, 
Tsouderos Y, Tugwell P, Reginster JY (2013) Health economics in the field of osteoarthritis: an expert's consensus paper from the European Society for Clinical and Economic Aspects of Osteoporosis and Osteoarthritis (ESCEO). Semin Arthritis Rheum 43:303-313. https://doi.org/10.1016/j.semarthrit.2013.07.003

8. D'Ambrosi R, Marciandi L, Frediani PV, Facchini RM (2016) Uncemented total hip arthroplasty in patients younger than 20 years. J Orthop Sci 21:500-506. https://doi.org/10.1016/j.jos. 2016.03.009

9. Sadoghi P, Liebensteiner M, Agreiter M, Leithner A, Bohler N, Labek G (2013) Revision surgery after total joint arthroplasty: a complication-based analysis using worldwide arthroplasty registers. J Arthroplast 28:1329-1332. https://doi.org/10.1016/j.arth. 2013.01.012

10. Neuprez A, Neuprez AH, Kaux JF, Kurth W, Daniel C, Thirion T, Huskin JP, Gillet P, Bruyere O, Reginster JY (2018) Early clinically relevant improvement in quality of life and clinical outcomes 1 year postsurgery in patients with knee and hip joint arthroplasties. Cartilage 9:127-139. https://doi.org/10.1177/1947603517743000

11. Neuprez A, Neuprez AH, Kurth W, Gillet P, Bruyere O, Reginster JY (2017) Profile of osteoarthritic patients undergoing hip or knee arthroplasty, a step toward a definition of the "need for surgery". Aging Clin Exp Res 30:315-321. https://doi.org/10.1007/s40520017-0780-1

12. Groll DL, To T, Bombardier C, Wright JG (2005) The development of a comorbidity index with physical function as the outcome. $\mathrm{J}$ Clin Epidemiol 58:595-602. https://doi.org/10.1016/j.jclinepi. 2004.10.018

13. Kellgren JH, Lawrence JS (1957) Radiological assessment of osteoarthrosis. Ann Rheum Dis 16:494-502

14. Bellamy N, Buchanan WW, Goldsmith CH, Campbell J, Stitt LW (1988) Validation study of WOMAC: a health status instrument for measuring clinically important patient relevant outcomes to antirheumatic drug therapy in patients with osteoarthritis of the hip or knee. J Rheumatol 15:1833-1840

15. Garratt AM, Ruta DA, Abdalla MI, Buckingham JK, Russell IT (1993) The SF36 health survey questionnaire: an outcome measure suitable for routine use within the NHS? BMJ 306:1440-1444

16. Rabin R, de Charro F (2001) EQ-5D: a measure of health status from the EuroQol Group. Ann Med 33:337-343

17. Losina E, Katz JN (2013) Total joint replacement outcomes in patients with concomitant comorbidities: a glass half empty or half full? Arthritis Rheum 65:1157-1159. https://doi.org/10.1002/art. 37903

18. Ramkumar PN, Navarro SM, Haeberle HS, Ng M, Piuzzi NS, Spindler KP (2018) No difference in outcomes 12 and 24 months after lower extremity total joint arthroplasty: a systematic review and meta-analysis. J Arthroplast 33:2322-2329. https://doi.org/10. 1016/j.arth.2018.02.056

19. Shan L, Shan B, Graham D, Saxena A (2014) Total hip replacement: a systematic review and meta-analysis on mid-term quality of life. Osteoarthr Cartil 22:389-406. https://doi.org/10.1016/j.joca. 2013.12.006

20. Shan L, Shan B, Suzuki A, Nouh F, Saxena A (2015) Intermediate and long-term quality of life after total knee replacement: a systematic review and meta-analysis. J Bone Joint Surg Am 97:156-168. https://doi.org/10.2106/JBJS.M.00372

21. Konopka JF, Lee YY, Su EP, McLawhorn AS (2018) Qualityadjusted life years after hip and knee arthroplasty: health-related quality of life after 12,782 joint replacements. JB JS Open Access 3:e0007. https://doi.org/10.2106/JBJS.OA.18.00007

22. Crawford CH, Glassman SD, Mummaneni PV, Knightly JJ, Asher AL (2016) Back pain improvement after decompression without fusion or stabilization in patients with lumbar spinal stenosis and clinically significant preoperative back pain. J Neurosurg Spine 25: 596-601. https://doi.org/10.3171/2016.3.SPINE151468
23. Hawker GA, Badley EM, Borkhoff CM, Croxford R, Davis AM, Dunn S, Gignac MA, Jaglal SB, Kreder HJ, Sale JE (2013) Which patients are most likely to benefit from total joint arthroplasty? Arthritis Rheum 65:1243-1252. https://doi.org/10.1002/art.37901

24. Frankel L, Sanmartin C, Conner-Spady B, Marshall DA, FreemanCollins L, Wall A, Hawker GA (2012) Osteoarthritis patients' perceptions of "appropriateness" for total joint replacement surgery. Osteoarthr Cartil 20:967-973. https://doi.org/10.1016/j.joca.2012. 05.008

25. Beswick AD, Wylde V, Gooberman-Hill R, Blom A, Dieppe P (2012) What proportion of patients report long-term pain after total hip or knee replacement for osteoarthritis? A systematic review of prospective studies in unselected patients. BMJ Open 2:e000435. https://doi.org/10.1136/bmjopen-2011-000435

26. Hofstede SN, Gademan MG, Vliet Vlieland TP, Nelissen RG, Marang-van de Mheen PJ (2016) Preoperative predictors for outcomes after total hip replacement in patients with osteoarthritis: a systematic review. BMC Musculoskelet Disord 17:212. https://doi. org/10.1186/s12891-016-1070-3

27. Tilbury C, Holtslag MJ, Tordoir RL, Leichtenberg CS, Verdegaal SH, Kroon HM, Fiocco M, Nelissen RG, Vlieland TPV (2016) Outcome of total hip arthroplasty, but not of total knee arthroplasty, is related to the preoperative radiographic severity of osteoarthritis. A prospective cohort study of 573 patients. Acta Orthop 87:67-71. https://doi.org/10.3109/17453674.2015.1092369

28. Schnurr C, Jarrous M, Gudden I, Eysel P, Konig DP (2013) Preoperative arthritis severity as a predictor for total knee arthroplasty patients' satisfaction. Int Orthop 37:1257-1261. https://doi.org/10. 1007/s00264-013-1862-0

29. Schilling CG, Dowsey MM, Petrie DJ, Clarke PM, Choong PF (2017) Predicting the long-term gains in health-related quality of life after total knee arthroplasty. J Arthroplast 32:395-401.e392. https://doi.org/10.1016/j.arth.2016.07.036

30. Peter WF, Dekker J, Tilbury C, Tordoir RL, Verdegaal SH, Onstenk R, Bénard MR, Vehmeijer SB, Fiocco M, Vermeulen HM, van der Linden-van der Zwaag H, Nelissen RG, Vliet Vlieland TP (2015) The association between comorbidities and pain, physical function and quality of life following hip and knee arthroplasty. Rheumatol Int 35:1233-1241. https://doi.org/10.1007/s00296-015-3211-7

31. Lalmohamed A, Vestergaard P, de Boer A, Leufkens HG, van Staa TP, de Vries F (2014) Changes in mortality patterns following total hip or knee arthroplasty over the past two decades: a nationwide cohort study. Arthritis Rheum 66:311-318. https://doi.org/10.1002/ art.38232

32. Frie KG, van der Meulen J, Black N (2012) Relationship between patients' reports of complications and symptoms, disability and quality of life after surgery. Br J Surg 99:1156-1163. https://doi. org/10.1002/bjs. 8830

33. Shadyab AH, Li W, Eaton CB, LaCroix AZ (2018) General and abdominal obesity as risk factors for late-life mobility limitation after total knee or hip replacement for osteoarthritis among women. Arthritis Care Res 70:1030-1038. https://doi.org/10.1002/acr. 23438

34. Dowsey MM, Spelman T, Choong PF (2016) Development of a prognostic nomogram for predicting the probability of nonresponse to total knee arthroplasty 1 year after surgery. J Arthroplast 31: 1654-1660. https://doi.org/10.1016/j.arth.2016.02.003

35. WHOQOL Group (1993) Study protocol for the World Health Organization project to develop a quality of life assessment instrument (WHOQOL). Qual Life Res 2:153-159. https://doi.org/10. 1007/BF00435734

36. Unverzagt S, Prondzinsky R, Peinemann F (2013) Single-center trials tend to provide larger treatment effects than multicenter trials: a systematic review. J Clin Epidemiol 66:1271-1280. https://doi. org/10.1016/j.jclinepi.2013.05.016 
37. Wright RW, Brand RA, Dunn W, Spindler KP (2007) How to write a systematic review. Clin Orthop Relat Res 455:23-29. https://doi. org/10.1097/BLO.0b013e31802c9098

38. Imam MA, Barke S, Stafford GH, Parkin D, Field RE (2014) Loss to follow-up after total hip replacement: a source of bias in patient reported outcome measures and registry datasets? Hip Int 24:465472. https://doi.org/10.5301/hipint.5000141

39. Rocheleau CM, Romitti PA, Sherlock SH, Sanderson WT, Bell EM, Druschel C (2012) Effect of survey instrument on participation in a follow-up study: a randomization study of a mailed questionnaire versus a computer-assisted telephone interview. BMC Public Health 12:579. https://doi.org/10.1186/1471-2458-12-579

40. Schwartz CE, Andresen EM, Nosek MA, Krahn GL, RRTC Expert Panel on Health Status Measurement (2007) Response shift theory: important implications for measuring quality of life in people with disability. Arch Phys Med Rehabil 88:529-536. https://doi.org/10. 1016/j.apmr.2006.12.032

Publisher's note Springer Nature remains neutral with regard to jurisdictional claims in published maps and institutional affiliations. 